\title{
Mercury pollution assessment in soils affected by industrial emissions using miniaturized ultrasonic probe extraction and ICP-MS
}

\author{
E. Bernalte $\cdot$ S. Salmanighabeshi $\cdot$ F. Rueda-Holgado $\cdot$ \\ M. R. Palomo-Marín · C. Marín-Sánchez • \\ F. Cereceda-Balic $\cdot$ E. Pinilla-Gil
}

Received: 29 April 2013/Revised: 26 July 2013/Accepted: 24 November 2013/Published online: 8 January 2014

(C) Islamic Azad University (IAU) 2013

\begin{abstract}
A combination of probe ultrasonic extraction, optimized by surface response methodology, and Inductively coupled plasma mass spectrometry (ICP-MS) detection is described in this work as an effective methodology for mercury monitoring in soils affected by industrial emissions. Minute amounts of samples (typically $20 \mathrm{mg}$ ) can be extracted in $3 \mathrm{~min}$ by $1 \mathrm{~mL}$ of HCl-based extracting solution, without risk of mercury losses, and sub sequentially assayed by ICP-MS. The method was successfully tested on soil standard reference materials and then applied to mercury monitoring in a large set of real soil samples collected during a long-term monitoring survey (2007-2011) around the industrial area of Puchuncaví, Chile. The method proved to be useful for investigation of spatial and temporal mercury variability in the area, showing an intermediate to high mercury contamination with potential impact on the surrounding ecosystem.
\end{abstract}

Keywords Mercury - Soil - Ultrasonic extraction · Inductively coupled plasma mass spectrometry · Hierarchical cluster analysis - Contamination indexes

E. Bernalte $(\varangle) \cdot$ S. Salmanighabeshi · F. Rueda-Holgado · M. R. Palomo-Marín · C. Marín-Sánchez · E. Pinilla-Gil Departamento de Química Analítica, Universidad de Extremadura, Avda. de Elvas, s/n, 06006 Badajoz, Spain e-mail: ebernalte@unex.es

F. Cereceda-Balic

Laboratorio de Química Ambiental (LQA), Centro de Tecnologías Ambientales (CETAM), Universidad Técnica Federico Santa María, Casilla 110-V, Valparaiso, Chile

\section{Introduction}

Mercury is regarded as one of the major hazardous trace metal impacting on the environment and public health because of its high volatility, toxicity, mobility, and great ability of bioaccumulation. It is released into the different environmental compartments from both natural and anthropogenic sources, where mercury in several chemical forms undergoes many biological, chemical, and photochemical reactions (Geng et al. 2008; García-Sánchez et al. 2009; Gao et al. 2012). Natural sources include volcanoes (Ferrara et al. 2000), geothermal activities (Loppi 2001), wild fires (Friedli et al. 2003), soil erosion, and oceans, whereas fossil fuel combustion (Grangeon et al. 2012), waste incineration, metal mining, refining and manufacturing (Wu et al. 2006), electronic, paper, pharmaceutical industries (Tack et al. 2005), and chlor-alkali plants (Southworth et al. 2004) are identified as the major sources of anthropogenic emission of $\mathrm{Hg}$ in the industrialized world. Currently, mercury pollution is recognized as a geographically widespread and persistent environmental problem (Pereira et al. 2008).

Soil is the primary terrestrial reservoir of persistent contaminants, playing an important role in the biogeochemical cycle of mercury, and acting both as a sink and a source of this metal to biota, atmosphere, and hydrological compartments (Reis et al. 2010). These facts make soil a useful matrix for the evaluation of the environmental impact of this element.

The need of accurate determination of mercury at the typically low levels found in environmental samples has prompted the development of a variety of highly sensitive and reliable analytical methodologies (Pereira et al. 2008). Cold vapor atomic absorption spectrometry (CV-AAS) has been most widely used because of its speed, simplicity, 
relative freedom from interferences, low operations costs, and high sensitivity, especially when mercury vapor is preconcentrated on gold by amalgamation (Krata and Bulska 2005). Other sensitive spectrometric techniques as cold vapor atomic fluorescence spectrometry (CV-AFS) (Guzmán-Mar et al. 2011) or inductively coupled plasma optical emission spectrometry (ICP-OES) (Shoaee et al. 2012) are frequently used for $\mathrm{Hg}$ determination. Also, many published methods are based on inductively coupled plasma mass spectrometry (ICP-MS), because of its excellent detection limits (Palomo Marín et al. 2011). On the other hand, stripping electroanalytical techniques are recently re-emerging as an attractive alternative for $\mathrm{Hg}$ determination in connection with low-cost, short analysis time, miniaturization and even suitability for field analysis (Bernalte et al. 2011, 2012a, b). Other techniques that enable direct analyses without sample pretreatment as instrumental neutron activation analysis (INAA) (Osawa et al. 2011), X-ray absorption spectroscopy (XAS), or $\mathrm{X}$-ray fluorescence (XRF) (Bernaus et al. 2006) are also cited in the literature for $\mathrm{Hg}$ determination.

Special attention is currently paid to the analytical sample preparation procedures in order to reduce solvent amounts, overall time, and cost (Tadeo et al. 2010). As a consequence, ultrasonic probe-assisted extraction has emerged as an effective way of sample treatment for elemental analysis in the environmental samples and is increasingly applied for the efficient, fast, and economic extraction of metal species. The focused cavitation reached by the ultrasonic energy around the probe increases the temperature, the pressure, and the oxidative energy of solvent radicals producing favorable extraction conditions when comparing with microwave-assisted extraction (Tadeo et al. 2010), enzymatic hydrolysis (Berzas Nevado et al. 2005), slurry preparation (Lemes and Wang 2009), or bath ultrasonic extraction (dos Santos et al. 2010). The ultrasonic probe has been scarcely studied as a pretreatment tool for mercury extraction from environmental samples, with some published results about applicability to dust (Palomo Marín et al. 2011; Bernalte et al. 2012b) and biological samples (López et al. 2010). A single application to soil and sediment samples, with final detection by CVAAS, has been reported (Collasiol et al. 2004).

In the present work, we have aimed to explore a simplified strategy based on the application of a miniaturized, fast, and efficient ultrasound probe-assisted extraction method coupled to ICP-MS for the determination of total mercury in large sets of soil samples. Applicability is demonstrated by the use of the method for mercury monitoring in soil samples collected at different locations around the industrial area of Puchuncaví-Ventanas (Chile) from 2007 to 2011. Previously unreported temporal and spatial variabilities of mercury content in these polluted areas, relevant for health and environmental risk assessment, are described.

\section{Materials and methods}

Chemicals and materials

All chemicals used for the preparation of stock and standard solutions were of analytical grade; $10 \mathrm{mg} \mathrm{L}^{-1}$ stock solution of $\mathrm{Hg}$ (II) (ICP quality) was supplied by PerkinElmer (Spain). Working solutions were prepared by dilution with ultrapure water $\left(18.2 \mathrm{M} \Omega \mathrm{cm}\right.$ at $\left.25{ }^{\circ} \mathrm{C}\right)$ obtained from an Ultramatic system (Wasserlab, Spain). Samples and dilute standard solutions were adjusted to $\mathrm{pH} 2$ with subboiled $\mathrm{HNO}_{3}$ obtained from a quartz distiller (Kürner, Germany) before ICP-MS analysis. Glassware was thoroughly conditioned for trace analysis by cleaning with hot nitric acid $(10 \%)$, rinsing with ultrapure water, drying, and keeping in hermetic plastic bags before use.

A Fritsch Pulverisette 6 planetary balls mill (Germany) equipped with zirconium dioxide vessels, and balls were used for soil samples milling.

Ultrasound-assisted extraction experiments were carried out with a Hielscher (Teltow, Germany) UP200S stand mounted ultrasonic device, fitted with a $200 \mathrm{~W}, 24 \mathrm{kHz}$ high-frequency generator and equipped with a S1 1-mmdiameter titanium sonotrode suitable for volumes between 0.1 and $5 \mathrm{~mL}$. The amplitude control of the ultrasonic processor allowed the vibrations at the probe to be set any desired level in the range of the nominal power from 10 to $100 \%$.

An Ortoalresa Digicen 21 (Madrid, Spain) centrifuge equipped with a hermetic closure rotor and a 24-microtube sample holder was used for separation of solid residues after ultrasonic extractions.

A PerkinElmer ELAN 9000 (Massachusetts, USA) quadrupole ICP-MS equipped with a cross-flow nebulizer (resistant to HF and particle clogging), a ryton scott spray chamber, a demountable quartz torch, a nickel skimmer and sampler cones, and a gold-plated ceramic quadrupole mass analyzer were used for mercury determination.

NIST Standard Reference Material ${ }^{\circledR}$ 2710a Montana Soil I was used for accuracy check.

The software package XLSTAT 2009.1.02 was used for performing the hierarchical cluster analysis.

Study site description

The study area was located around the industrial complex of Puchuncaví-Ventanas. The Puchuncaví valley, a Mediterranean climate region placed in the coastal area of central Chile $\left(71^{\circ} 24^{\prime} \mathrm{S}, 32^{\circ} 40^{\prime} \mathrm{N}\right)$, is characterized by 


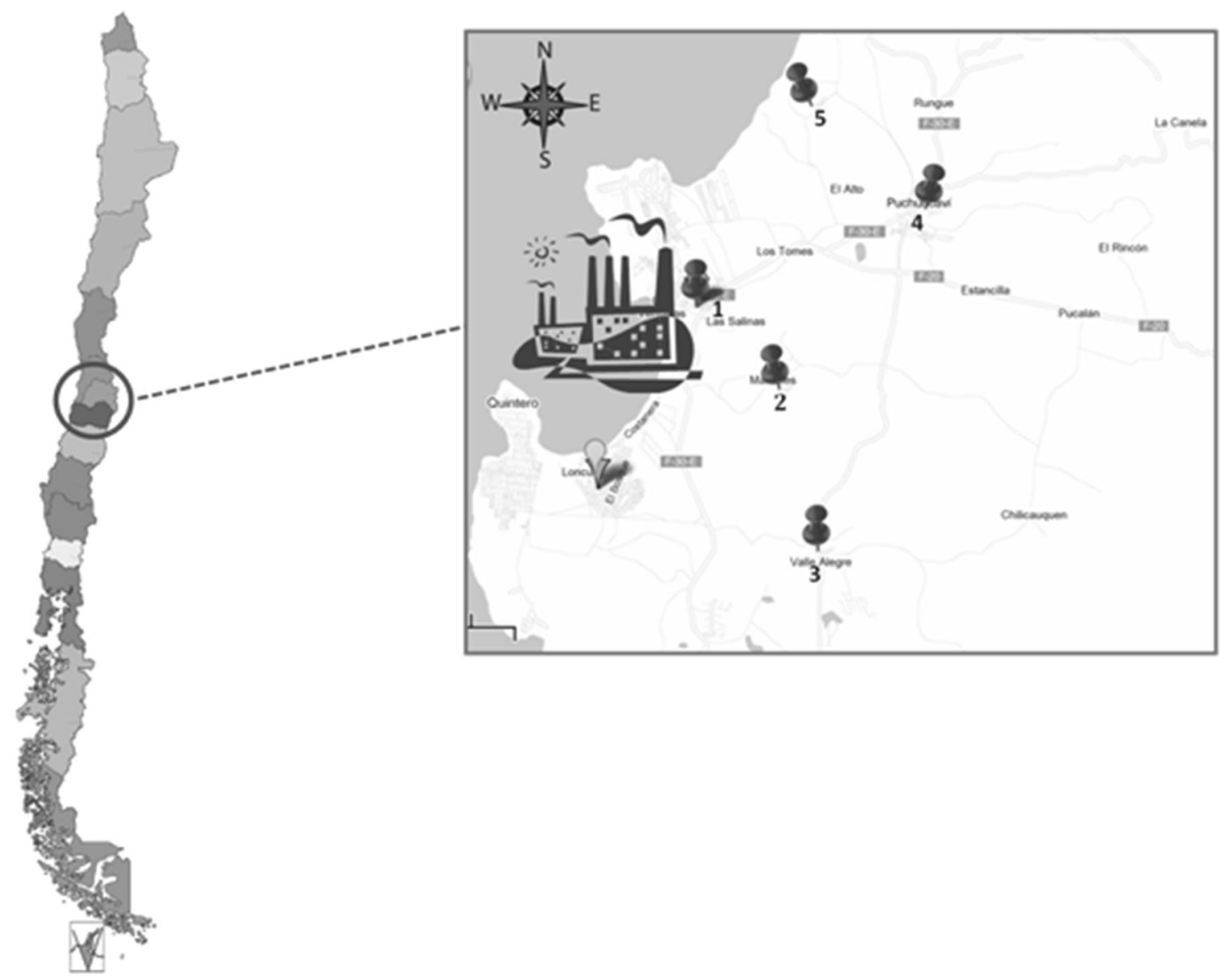

Fig. 1 Soil sampling locations at the Puchuncaví Valley, Chile: 1 La Greda, 2 Los Maitenes, 3 Valle Alegre, 4 Puchuncaví, 5 reference area

marked pollution due to the historical discharge of gaseous pollutants and atmospheric particulates, and deposition of metal-rich particles from diverse industrial facilities including coal-fired power plants, a copper refinery and smelter, natural gas terminals, and cement companies (Neaman et al. 2009, 2012). Apart from the industrial activity, the study area is mainly agricultural, with scarce rural population living in small villages. Five sampling areas were selected to evaluate the impact of mercury in soils surrounding the industrial complex. As depicted in Fig. 1, La Greda (LG), Los Maitenes (LM), Puchuncaví (PU), and Valle Alegre (VA) sampling sites are located around the industrial complex at different distances and different degrees of influence from the prevalent SW winds in the zone. The sampling points were located in the vicinity of small villages. A reference rural area was selected north to the study site (RF).

Sample collection and preparation

A total of 125 surface soil samples were collected in the study area (LG, LM, PU, VA, RF) during five monitoring campaigns carried out in summer 2007, 2008, 2009, 2010, and 2011. Five samples were taken around each sampling zone for each sampling campaign. These activities are in the frame of a large-scale and long-term ongoing environmental monitoring program in the area. For sampling, $1 \mathrm{~m}^{2}$ surface was delimited and the extraneous matter (stones, leafs, seeds, or roots) was eliminated. Soil samples were collected to a depth of $5-10 \mathrm{~cm}$ by using a hand polypropylene drill. Approximately $3 \mathrm{~kg}$ of sample was extracted with a plastic spade, placed into a conditioned plastic cube. The cube was closed and transferred to the laboratory.

In the laboratory, soil samples were appropriately dried in stove by heating at $50{ }^{\circ} \mathrm{C}$ for $72 \mathrm{~h}$ and then sieved through a polypropylene $2 \mathrm{~mm}$ mesh. Soil subsamples were mechanically homogenized in a planetary mill at 500 r.p.m for $15 \mathrm{~min}$ and manually sieved to $0.2 \mathrm{~mm}$ using a stainless steel mesh. The samples were then stored in the fridge $\left(4{ }^{\circ} \mathrm{C}\right)$ until analysis.

For the ultrasonic extraction, an appropriate amount of soil sample $(20 \mathrm{mg})$ was accurately weighed in a $1.5-\mathrm{mL}$ conical bottom Eppendorf micro-centrifuge tube with snap 
cap; $1 \mathrm{~mL}$ of extraction reagent $(\mathrm{HCl})$ was added, and the titanium ultrasonic probe was immersed. Then, the sonication of the samples was started at room temperature. The focused ultrasonic extraction of $\mathrm{Hg}$ was carried out under the experimental conditions developed in a previous published work (Bernalte et al. 2012b). Briefly, the optimization of the sonication parameters was achieved through the application of a face-centered cube central composite design of experiments (FCCD), and the optimum values were as follows: $55 \%$ sonication amplitude, $3.2 \mathrm{~min}$ sonication time, and $8.13 \mathrm{M}$ hydrochloric acid concentration. After sonication, the samples were centrifuged for $15 \mathrm{~min}$ at 5,000 r.p.m. For the final determination of $\mathrm{Hg}$ by ICPMS, $0.5 \mathrm{~mL}$ of the supernatant was transferred to a volumetric flask and the final volume was made up to $10 \mathrm{~mL}$ with $5 \% \mathrm{HNO}_{3}$. Certified reference material and blank samples were treated in the same way.

\section{Determination of mercury by ICP-MS}

The sample extracts were assayed by a standard ICP-MS protocol for the determination of total mercury as follows: RF power $1,000 \mathrm{~W}$, Ar plasma flow rate $1 \mathrm{~L} \mathrm{~min}^{-1}$, washing time $35 \mathrm{~s}(\mathrm{~s})$, and 3 replicates per sample. The most abundant mercury isotope ${ }^{202} \mathrm{Hg}$ was used for data evaluation. Quantification was performed by calibration with mercury standard solutions. Blank samples were placed among the extracts of the soil samples throughout the analysis by ICP-MS to check the possible memory effect described for routine analysis of mercury (Krata and Bulska 2005), and no significant concentrations of mercury were finally quantified in blank samples. Mercury concentrations in soil samples are expressed in dry soil weight terms.

\section{Contamination indexes}

The index of geoaccumulation $\left(I_{\text {geo }}\right)$, the enrichment factor $(\mathrm{EF})$, and the contamination factor $\left(C_{\mathrm{f}}\right)$ were calculated according to the definition given by Loska et al. (2004). The index of geoaccumulation was computed from Eq. (1):

$I_{\text {geo }}=\log _{2}\left(C_{n} / 1.5 B_{n}\right)$

where $C_{n}$ is the measured concentration of the element in the soil sampled and $B_{n}$ is the geochemical background value in the Earth's crust. Reference background values used were average mercury levels in the upper crustal crust as described by Wedepohl (1995). The $I_{\text {geo }}$ classifies the sampling locations into seven classes as follows: $\left(I_{\text {geo }} \leq 0\right)$ practically uncontaminated; $\left(0<I_{\text {geo }}<1\right)$ uncontaminated to moderately contaminated; $\left(1<I_{\text {geo }}<2\right)$ moderately contaminated; $\left(2<I_{\text {geo }}<3\right)$ moderately to heavily contaminated; $\left(3<I_{\text {geo }}<4\right)$ heavily contaminated; $\left(4<I_{\text {geo }}<5\right)$ heavily to extremely contaminated; and $\left(5 \leq I_{\text {geo }}\right)$ extremely contaminated.

The enrichment factor (EF) was based on the standardization of a tested element against a reference element, characterized by low occurrence variability. In this study, soil concentration of $\mathrm{Sr}$, measured in all samples during a multielemental soil monitoring campaign carried out in the study area, was used. The value of the enrichment factor was calculated according to Eq. (2):

$\mathrm{EF}=\frac{\frac{C_{n}(\text { sample })}{C_{\text {ref }}(\text { sample })}}{\frac{B_{n}(\text { background })}{B_{\text {ref }}(\text { background })}}$

Where $C_{n}$ (sample) is the content of the examined element in the examined environment, $C_{\text {ref }}$ (sample) is the content of the reference element in the examined environment, $B_{n}$ (background) is the content of the examined element in the reference environment, and $B_{\text {ref }}$ (background) is the content of the reference element in the reference environment.

Five contamination categories are recognized on the basis of the enrichment factor: $\mathrm{EF}<2$ (deficiency to minimal enrichment), $\mathrm{EF}=2-5$ (moderate enrichment), $\mathrm{EF}=5-20$ (significant enrichment), $\mathrm{EF}=20-40$ (very high enrichment), and $\mathrm{EF}>40 \quad$ (extremely high enrichment).

The contamination factor $\left(C_{\mathrm{f}}\right)$ was calculated by Eq. (3):

$C_{\mathrm{f}}=\frac{C_{n}(\text { sample })}{B_{n}(\text { background })}$

Four contamination categories are defined for $C_{\mathrm{f}}$ : $C_{\mathrm{f}}<1$ (low contamination factor indicating low contamination); $1 \leq C_{\mathrm{f}}<3$ (moderate contamination factor); $3 \leq C_{\mathrm{f}}<6$ (considerable contamination factor); and $C_{\mathrm{f}}>6$ (very high contamination factor).

Human risk assessment with attention to metal contaminated soil by ingestion was performed calculating the non-cancer toxic risk. Average daily dose (ADD) was calculated as USEPA's suggested (1993) by Eq. (4):

$\mathrm{ADD}=[C \times \operatorname{IngR} \times \mathrm{EF} \times \mathrm{ED}] /[\mathrm{BW} \times \mathrm{AT}]$

where $C$ is the contaminant content in soil $\left(\mathrm{mg} \mathrm{kg}^{-1}\right)$, conservative estimates of ingestion rates (IngR) were chosen for children $\left(200 \mathrm{mg} \mathrm{day}^{-1}\right)$ and adults $\left(100 \mathrm{mg} \mathrm{day}^{-1}\right)$. Average body weight $(\mathrm{BW})$ was chosen $60 \mathrm{~kg}$ for adults and $16 \mathrm{~kg}$ for children. Exposure frequency (EF) was 350 days year ${ }^{-1}$, exposure duration (ED) was 6 years, and average time (AT) was 2,190 days.

So, non-cancer toxic risk was calculated by calculating the hazard quotient (HQ) by Eq. (5):

$\mathrm{HQ}=\frac{\mathrm{ADD}}{\mathrm{RFD}}$ 
where RFD is the toxicity value for estimating non-cancer effects from oral exposure, which is an estimate of the highest dose that adverse non-cancer effect. In this study, considering the chloride mercury oral RFD was used $0.0003 \mathrm{mg} \mathrm{kg}^{-1}$ day $^{-1}$, as standard value. Therefore, $\mathrm{HQ} \leq 1$ suggests unlikely adverse health effects, HQ $>1$ suggests the probability of adverse health effects, and HQ $>10$ is considered to be high chronic risk (MezaMontenegro et al. 2012).

\section{Results and discussion}

Validation of the methodology

As mentioned above, the ultrasonic probe extraction method used in this work was previously optimized by response surface methodology and successfully applied for the determination of $\mathrm{Hg}$ in indoor dust samples (Bernalte et al. 2012b). To ensure the reliability of the methodology for the extraction of the analyte from soil samples, a certified reference material was selected to test the extraction protocol. Therefore, a set of 9 subsamples of the standard reference material NIST 2710a Montana Soil was extracted and analyzed by using a standardized ICP-MS methodology for accuracy check. A very good agreement between certified concentration of $\mathrm{Hg}\left(9.88 \pm 0.21 \mathrm{mg} \mathrm{kg}^{-1}\right)$ and measured concentration $\left(10.62 \pm 0.31 \mathrm{mg} \mathrm{kg}^{-1}\right)$ was found. In terms of percentage of recovery, the results obtained were in the range of $88-118 \%$.

The limit of detection (LOD) of the method was calculated according to the IUPAC definition by processing a set of 10 blank samples in the same way as the standard reference material, and a value of $0.25 \mathrm{ng} \mathrm{mL}^{-1}$ was obtained. This value is similar to previously reported detection limits for the determination of mercury in soil and sediments by ultrasonic probe extraction followed by CV-AAS, $0.2 \mathrm{ng} \mathrm{mL}^{-1}$ (Collasiol et al. 2004), and low enough for measuring the expected concentrations in polluted and unpolluted soils.

\section{Application to soil samples}

The optimized probe ultrasonic-assisted extraction was applied to the 125 soil samples collected within the Puchuncaví industrial zone and reference areas, and soil extracts were analyzed by ICP-MS as previously described. The results obtained from the samples collected around the industrial zone are summarized in Table 1 . The 25 samples collected at the reference area gave values of mercury concentration below the LOD.

Considering the whole sampling period and the four locations around the industrial complex (LG, LM, PU and $\mathrm{VA}$ ), the mean $\mathrm{Hg}$ concentration in the sampled soils was $0.408 \mathrm{mg} \mathrm{kg}^{-1}$ (range from <LOD to $3.777 \mathrm{mg} \mathrm{kg}^{-1}$ ). Highest values of $\mathrm{Hg}$ were measured in La Greda soils (mean of all samples $0.795 \mathrm{mg} \mathrm{kg}^{-1}$ ), probably due to its geographical situation in the vicinity to the emission sources from the industrial area and under the influence of the dominant SW winds. Relatively high concentrations of $\mathrm{Hg}$ were also found in the soil samples collected from Los Maitenes (mean $0.346 \mathrm{mg} \mathrm{kg}^{-1}$ ) and Puchuncaví (mean $0.288 \mathrm{mg} \mathrm{kg}^{-1}$ ) locations. Los Maitenes is closer to the industrial complex than Puchuncaví (Fig. 1), but the last is more affected by pollutant transport by the dominant winds. The lowest $\mathrm{Hg}$ values found in the soils around the industrial complex were measured in Valle Alegre samples

Table 1 Concentration of mercury in soils from the study areas

\begin{tabular}{lllllll}
\hline Year & $\mathrm{Hg}\left(\mathrm{mg} \mathrm{kg}^{-1}\right)$ & LG & LM & PU & VA & Whole study area \\
\hline 2007 & Range & $<$ LOD-0.332 & $<$ LOD-0.851 & $<$ LOD-0.125 & $<$ LOD-0.329 & $<$ LOD-0.851 \\
& Mean & 0.217 & 0.488 & 0.178 & 0.193 & 0.269 \\
2008 & Range & $<$ LOD-0.722 & $0.122-0.696$ & $<$ LOD-0.301 & $0.089-0.125$ & $<$ LOD-0.722 \\
& Mean & 0.321 & 0.285 & 0.199 & 0.109 & 0.228 \\
2009 & Range & $0.714-3.458$ & $0.287-1.450$ & $0.338-1.410$ & $0.163-0.563$ & $0.163-3.458$ \\
& Mean & 1.810 & 0.597 & 0.638 & 0.301 & 0.836 \\
2010 & Range & $0.308-3.777$ & $0.141-0.337$ & $<$ LOD-0.159 & $<$ LOD & $<$ LOD-3.777 \\
& Mean & 1.496 & 0.246 & 0.138 & $<$ LO & 0.627 \\
Whole period & Range & $0.124-0.153$ & $0.080-0.125$ & $<$ LOD & $<$ LOD & $<$ LOD-0.153 \\
& Mean & 0.129 & 0.117 & $<$ LOD & $<$ LOD & 0.123 \\
& Range & $<$ LOD-3.777 & $<$ LOD-1.450 & $<$ LOD-1.410 & $<$ LOD-0.563 & $<$ LOD-3.777 \\
\end{tabular}

Five samples per sampling campaign in each location

$L G$ La Greda, $L M$ Los Maitenes, PU Puchuncaví, VA Valle Alegre 
Fig. 2 Mercury concentration in soils at the Puchuncaví industrial area

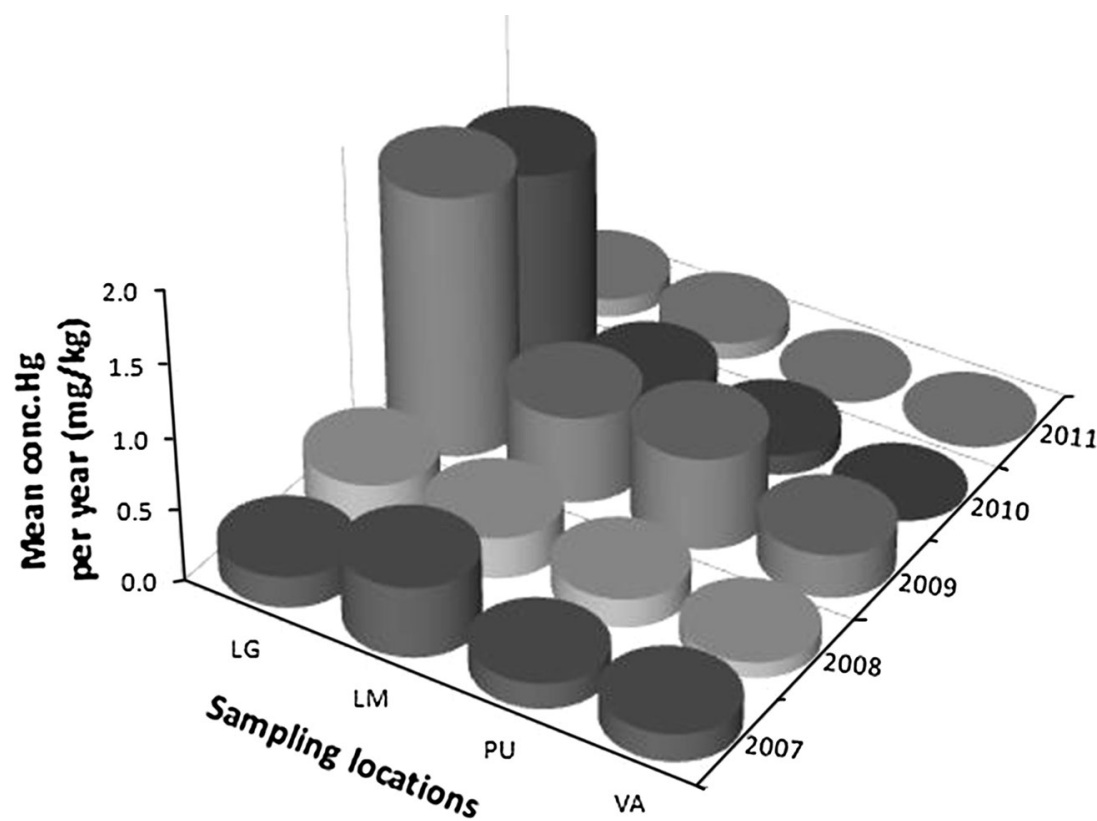

Table 2 Classification of sampling campaigns by hierarchical cluster analysis of mercury concentrations (yearly mean on each location)

\begin{tabular}{lllll}
\hline Groups & & & & \\
\hline C1 & C2 & C3 & C4 & C5 \\
LG07 & LM07 & RF07 & LG09 & LG10 \\
PU07 & LM09 & VA08 & & \\
VA07 & PU09 & RF08 & & \\
LG08 & & RF09 & & \\
LM08 & & PU10 & & \\
PU08 & & VA10 & & \\
VA09 & & RF10 & & \\
LM10 & & LG11 & & \\
& & LM11 & \\
& & PU11 & \\
& & VA11 & \\
& & RF11 & \\
\hline
\end{tabular}

(mean $0.201 \mathrm{mg} \mathrm{kg}^{-1}$ ), located $8 \mathrm{~km}$ south to the industrial complex.

The distribution of mercury in the selected sampling points along the study period 2007-2011 is presented in Fig. 2. A significant temporal variability in soil mercury concentration is observed in each sampling location during the period studied (2007-2011), with maximum values observed in 2009 and 2010 at the most polluted place (La Greda). Mercury concentration at Los Maitenes, Puchuncaví and Valle Alegre also shows a maximum in 2009. The decay of mercury concentrations in all locations during the 2010-2011 sampling campaigns could be assigned to contamination prevention policies that are progressively being implemented in the industrial area.

In order to explore spatial and temporal correlations of the soil samples attending to the mercury content, hierarchical cluster analysis (HCA) of the yearly mean of mercury concentration in each location was performed by using Euclidean distance and the Ward agglomerative algorithm. For this statistical analysis, the concentration of mercury in samples below the LOD limit was assumed to be one-half of the calculated LOD.

As shown in Table 2 and Fig. 3, the HCA test classified the sampling campaigns in five groups. Groups $\mathrm{C} 4$ and $\mathrm{C} 5$ are formed by the 2009 and 2010 sampling campaigns in La Greda (LG09 and LG10), which provided the highest mercury levels. Group C2 aggregates sampling campaigns where intermediate mercury levels were measured, including the 2009 sampling campaigns at Los Maitenes (LM09) and Puchuncaví (PU09) and also the 2007 sampling campaign at Los Maitenes (LM07). Groups C1 and C3 include the samples with the lower mercury levels, including all the Valle Alegre and reference area sampling campaigns.

\section{Mercury pollution assessment}

A significant degree of heavy metal pollution around the Puchuncaví industrial area has been demonstrated by different authors along a wide set of experimental studies on rainwater (De Gregori et al. 2002), soils (De Gregori et al. 2003; Ginocchio et al. 2004), and biomonitors (Ginocchio 2000; Neaman et al. 2012). Typical heavy metal pollutants have been investigated including lead, cadmium, copper, 
Fig. 3 Dendogram depicting the hierarchical clustering of yearly average of mercury concentration at the sampling locations. See Table 2 for explanation of categories

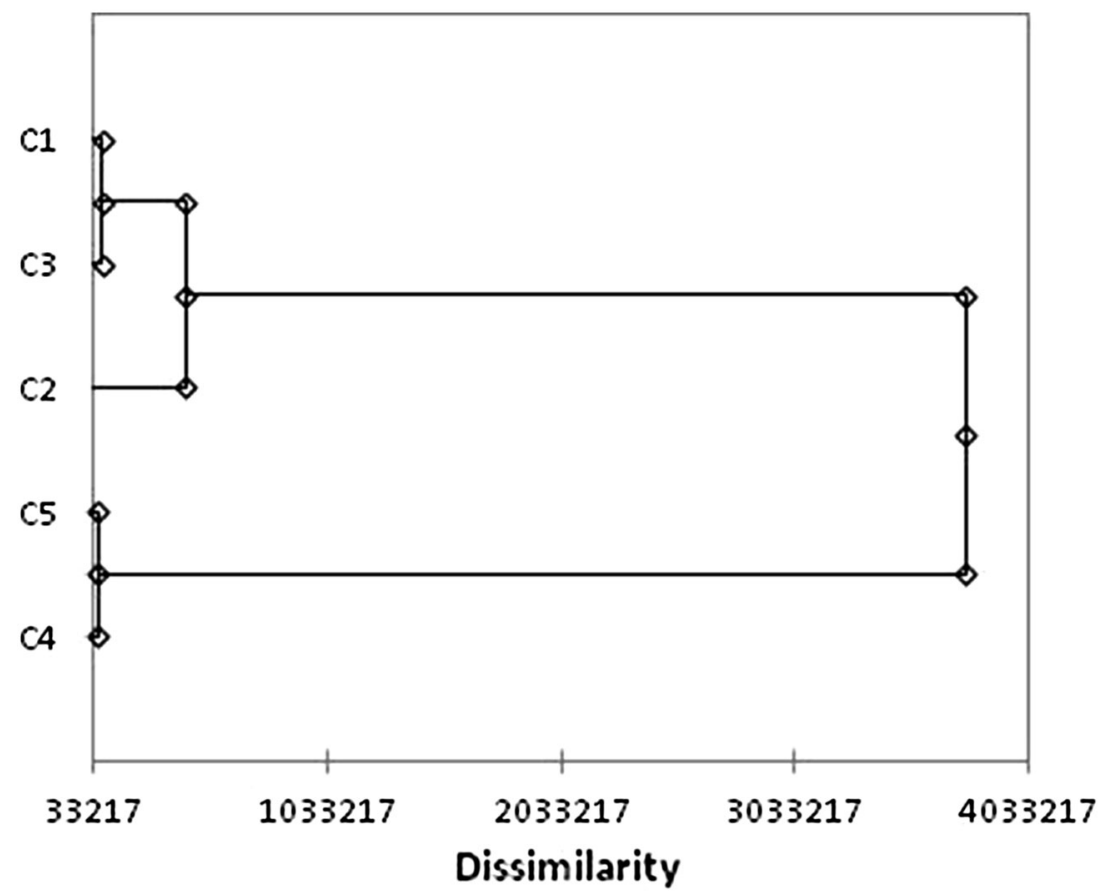

Table 3 Mercury concentrations in topsoils from some rural, industrial, and mercury-related industrial activities around the world

\begin{tabular}{|c|c|c|c|c|}
\hline Location & Activity & Mean $\left(\mathrm{mg} \mathrm{kg}^{-1}\right)$ & Range $\left(\mathrm{mg} \mathrm{kg}^{-1}\right)$ & Reference \\
\hline \multicolumn{5}{|l|}{ Rural areas } \\
\hline South Carolina (USA) & Farmland & 0.04 & $0-0.19$ & Salminen et al. (2005) \\
\hline Europe & Random & 0.061 & $0.005-1.35$ & Senesil et al. (1999) \\
\hline Zhengding County (China) & Farmland & 0.08 & $0.02-0.37$ & Shoaee et al. (2012) \\
\hline World & Background & & $0.01-0.03$ & Southworth et al. (2004) \\
\hline \multicolumn{5}{|l|}{ Industrial areas } \\
\hline Guangdom (China) & Petrochemical complex & 0.61 & $0.028-2.4$ & Tack et al. (2005) \\
\hline Beijing (China) & Chemical industries & 4.85 & $0.22-76.27$ & Tadeo et al. (2010) \\
\hline Gebze (Turkey) & Industrial complex & 0.102 & $0.009-2.721$ & Terán-Mita et al. (2013) \\
\hline Shenyang (China) & Industrial complex & 0.39 & $0.06-1.34$ & US EPA (1993) \\
\hline \multicolumn{5}{|l|}{ Hg-related industrial areas } \\
\hline Grenoble (France) & Chlor-alkali plant & & $0.05-10$ & US EPA (2012) \\
\hline Estarreja (Portugal) & Chlor-alkali plant & & $0.010-91$ & Wedepohl (1995) \\
\hline Apolobamba (Bolivia) & Small scale gold mining & & $0.5-48.6$ & Wu et al. (2006) \\
\hline \multicolumn{5}{|l|}{ This study } \\
\hline Whole study area & & 0.408 & $<$ LOD-3.777 & \\
\hline La Greda & & 0.795 & $<$ LOD-3.777 & \\
\hline Los Maitenes & & 0.346 & $<$ LOD-1.450 & \\
\hline Puchuncaví & & 0.288 & $<$ LOD-1.410 & \\
\hline Valle Alegre & & 0.201 & $<$ LOD-0.563 & \\
\hline
\end{tabular}

zinc, selenium, arsenic and antimony, but no results have been published to date about mercury pollution in the area. Our experimental results were compared with mercury levels in topsoils from rural, industrial, and mercury-related industrial locations around the world, as measured in recent studies by different authors (Table 3). The Puchuncaví Valley soils mercury contents are higher than the levels measured in rural areas (Senesil et al. 1999; Salminen et al. 2005; Aelion et al. 2008; Yang et al. 2009), but roughly similar to recently measured values in comparable 
Table 4 Indexes of geoaccumulation $\left(I_{\mathrm{geo}}\right)$, enrichment factors $(\mathrm{EF})$, and contamination factors $\left(C_{\mathrm{f}}\right)$ for mercury in soils at the Puchuncaví Valley

\begin{tabular}{lllllll}
\hline Index & & \multicolumn{2}{l}{ Sampling locations } & & \\
\cline { 3 - 7 } & & LG & LM & PU & VA & Whole study area \\
\hline$I_{\text {geo }}$ & Value & 3.30 & 2.06 & 1.70 & 1.06 & 2.03 \\
& Contamination & Heavy & Moderate to heavy & Moderate & Moderate & Moderate to heavy \\
EF & Value & 17.05 & 9.01 & 8.76 & 6.17 & 10.25 \\
& Enrichment & Significant & Significant & Significant & Significant & Significant \\
$C_{\mathrm{f}}$ & Value & 14.76 & 6.24 & 4.88 & 3.12 & 7.25 \\
& Contamination & Very high & Very high & Considerable & Considerable & Very high \\
\hline
\end{tabular}

industrial areas from China and Turkey (Li et al. 2009, 2013; Luo et al. 2009; Yaylali-Abanuz 2011). The soil mercury contents measured in the study area are, however, lower than those found at locations with industrial activities implying mercury use, like chlor-alkali plants (Reis et al. 2009; Grangeon et al. 2012) or artisanal gold mining (Terán-Mita et al. 2013). The mercury concentrations found at Puchuncaví Valley soils do not exceed threshold levels established for soil pollution assessment, e.g., by The Netherlands (intervention value, $36 \mathrm{mg} \mathrm{kg}^{-1}$ ) (Leefomgeving 2009), US EPA (screening value for residential soils, $23 \mathrm{mg} \mathrm{kg}^{-1}$ ) (US EPA 2012), or Canada (guideline value for residential soils, $6.6 \mathrm{mg} \mathrm{kg}^{-1}$ ) (Canadian Council of Ministers of the Environment 2007).

Mercury pollution in the study area soils was further explored by using common contamination indexes: the index of geoaccumulation $\left(I_{\mathrm{geo}}\right)$, the enrichment factor $(\mathrm{EF})$, and the contamination factor $\left(C_{\mathrm{f}}\right)$. The calculated indexes and corresponding contamination categories are summarized in Table 4. $I_{\text {geo }}$ values range from heavy contamination in La Greda sampling location to moderate in Puchuncaví and Valle Alegre locations, and a moderate to heavy contamination is assigned to Los Maitenes and to the whole study area. The mercury EF values are significant in all locations. The $C_{\mathrm{f}}$ values indicate very high contamination in La Greda and Los Maitenes and also for the whole study area, whereas Puchuncaví and Valle Alegre are classified as moderately contaminated. Due to the potential risk of mercury pollution in the soils of Puchuncaví Valley, with potential impact to the whole ecosystem, pollution prevention and remediation measurements seem essential, especially in the areas close to the industrial facilities.

Assessment of non-cancer risk carried out by using the HQ parameter determines that in the whole study area, there are no health effects for children and adults because of the results obtained for HQ were less than 1. HQ parameter calculated for evaluating the children exposure of $\mathrm{Hg}$ in $\mathrm{La}$ Greda (0.03) was substantially higher comparing with the other locations (0.01), in spite of the result shows also unlikely health affects in the area.

\section{Conclusion}

Ultrasonic probe-assisted extraction optimized by response surface methodology offers a fast, easy, efficient, and miniaturized sample preparation for the determination of mercury in soil samples. The combination of the probe ultrasonic extraction with ICP-MS determination results in a reliable and effective methodology for mercury monitoring in soils. The effectiveness of the proposed methodology has been demonstrated by the analysis of standard reference materials and by application to mercury pollution assessment in a long-term industrial soil monitoring campaign in the Puchuncaví Valley, Chile. Intermediate to high levels of mercury contamination have been detected, indicating an ecological risk of mercury pollution in the area.

Acknowledgments This work is supported by the Spanish Agency of International Cooperation for Development (AECID project A1/ 037813/11) and the Spanish Ministry of Science and Innovation (project CTQ2011-25388). We acknowledge a grant from Junta de Extremadura, Spain (PRE09107). The authors thank N. Ríos for her technical assistance with soil samples processing.

\section{References}

Aelion CM, Davis HT, McDermott S, Lawson AB (2008) Metal concentrations in rural topsoil in South Carolina: potential for human health impact. Sci Total Environ 402:149-156

Bernalte E, Marín Sánchez C, Pinilla Gil E (2011) Determination of mercury in ambient water samples by anodic stripping voltammetry on screen-printed gold electrodes. Anal Chim Acta 689:60-64

Bernalte E, Marín Sánchez C, Pinilla Gil E (2012a) Gold nanoparticles-modified screen-printed carbon electrodes for anodic 
stripping voltammetric determination of mercury in ambient water samples. Sens Actuators B Chem 161:669-674

Bernalte E, Marín Sánchez C, Pinilla Gil E (2012b) Determination of mercury in indoor dust samples by ultrasonic probe microextraction and stripping voltammetry on gold nanoparticles-modified screen-printed electrodes. Talanta 87:187-192

Bernaus A, Gaona X, van Ree D, Valiente M (2006) Determination of mercury in polluted soils surrounding a chlor-alkali plant: direct speciation by X-ray absorption spectroscopy techniques and preliminary geochemical characterisation of the area. Anal Chim Acta 565:73-80

Berzas Nevado JJ, Rodríguez Martín-Doimeadios RC, Guzmán Bernardo FJ, Jiménez Moreno M (2005) Determination of mercury species in fish reference materials by gas chromatography-atomic fluorescence detection after closed-vessel microwave-assisted extraction. J Chromatogr A 1093:21-28

Canadian Council of Ministers of the Environment (2007) Canadian soil quality guidelines for the protection of environmental and human health, Update 7.0

Collasiol A, Pozebon D, Maia SM (2004) Ultrasound assisted mercury extraction from soil and sediment. Anal Chim Acta 518:157-164

De Gregori I, Lobos MG, Pinochet H (2002) Selenium and its redox speciation in rainwater from sites of Valparaíso region in Chile, impacted by mining activities of copper ores. Water Res 36:115-122

De Gregori I, Fuentes E, Rojas M, Pinochet H, Potin-Gautier M (2003) Monitoring of copper, arsenic and antimony levels in agricultural soils impacted and non-impacted by mining activities, from three regions in Chile. $\mathrm{J}$ Environ Monit 5:287-295

dos Santos EJ, Herrmann AB, Vieira F, Sato CS, Corrêa QB, Maranhão TA, Tormen L, Curtius AJ (2010) Determination of $\mathrm{Hg}$ and $\mathrm{Pb}$ in compact fluorescent lamp by slurry sampling inductively coupled plasma optical emission spectrometry. Microchem J 96:27-31

Ferrara R, Mazzolai B, Lanzillotta E, Nucaro E, Pirrone N (2000) Volcanoes as emission sources of atmospheric mercury in the Mediterranean basin. Sci Total Environ 259:115-121

Friedli HR, Radke LF, Lu JY, Banic CM, Leaitch WR, Macpherson JI (2003) Mercury emissions from burning of biomass from temperate North American forests: laboratory and airborne measurements. Atmos Environ 37:253-267

Gao Y, Shi Z, Long Z, Wu P, Zheng C, Hou X (2012) Determination and speciation of mercury in environmental and biological samples by analytical atomic spectrometry. Microchem $\mathrm{J}$ 103:1-14

García-Sánchez A, Murciego A, Álvarez-Ayuso E, Santa Regina I, Rodríguez-González MA (2009) Mercury in soils and plants in an abandoned cinnabar mining area (SW Spain). J Hazard Mater 168:1319-1324

Geng W, Nakayima T, Takanashi H (2008) Determination of mercury in ash and soil samples by oxygen flask combustion method-cold vapor atomic fluorescence spectrometry (CVAFS). J Hazard Mater 154:325-330

Ginocchio R (2000) Effects of a copper smelter on a grassland community in the Puchuncav' $́$ Valley, Chile. Chemosphere 41:15-23

Ginocchio R, Carvallo G, Toro I, Bustamante E, Silva Y, Sepúlveda N (2004) Micro-spatial variation of soil metal pollution and plant recruitment near a copper smelter in Central Chile. Environ Pollut 127:343-352

Grangeon S, Guédron S, Asta J, Sarret G, Charlet L (2012) Lichen and soil as indicators of an atmospheric mercury contamination in the vicinity of a chlor-alkali plant (Grenoble, France). Ecol Indic 13:178-183
Guzmán-Mar JL, Hinojosa-Reyes L, Serra AM, Hernández-Ramírez A, Cerdà V (2011) Applicability of multisyringe chromatography coupled to cold-vapor atomic fluorescence spectrometry for mercury speciation analysis. Anal Chim Acta 708:11-18

Krata A, Bulska E (2005) Critical evaluation of analytical performance of atomic absorption spectrometry and inductively coupled plasma mass spectrometry for mercury determination. Spectrochim Acta B 60:345-350

Leefomgeving R (2009) Soil remediation circular. Environmental Data Management Software (Australia)

Lemes M, Wang F (2009) Methylmercury speciation in fish muscle by HPLC-ICP-MS following enzymatic hydrolysis. J Anal At Spectrom 24:663-668

Li J, Lu Y, Yin W, Gan H, Zhang C, Deng X, Lian J (2009) Distribution of heavy metals in agricultural soils near a petrochemical complex in Guangzhou, China. Environ Monit Assess 153:365-375

Li X, Liu L, Wang Y, Luo G, Chen X, Yang X, Hall MHP, Guo R, Wang H, Cui J, He X (2013) Heavy metal contamination of urban soil in an old industrial city (Shenyang) in Northeast China. Geoderma 192:50-58

López I, Cuello S, Cámara C, Madrid Y (2010) Approach for rapid extraction and speciation of mercury using a microtip ultrasonic probe followed by LC-ICP-MS. Talanta 82:594-599

Loppi S (2001) Environmental distribution of mercury and other trace elements in the geothermal area of Bagnore (Mt. Amiata, Italy). Chemosphere 45:991-995

Loska K, Wiechula D, Korus I (2004) Metal contamination of farming soils affected by industry. Environ Int 30:159-165

Luo W, Lu Y, Wang B, Tong X, Wang G, Shi Y, Wang T, Giesy JP (2009) Distribution and sources of mercury in soils from former industrialized urban areas of Beijing, China. Environ Monit Assess 158:507-517

Meza-Montenegro MM, Gandolfi AJ, Santana-Alcántar ME, Klmecki WT, Gómez A, Mendivil-Quijada H, Valencia M, MezaFigueroa D (2012) Metals in residential soils and cumulative risk assessment in Yaqui and Mayo agricultural valleys, northern Mexico. Sci Total Environ 433:472-481

Neaman A, Reyes L, Trolard F, Bourrié G, Sauvé S (2009) Copper mobility in contaminated soils of the Puchuncaví valley, central Chile. Geoderma 150:359-366

Neaman A, Huerta S, Sauvé S (2012) Effects of lime and compost on earthworm (Eisenia fetida) reproduction in copper and arsenic contaminated soils from the Puchuncavi Valley, Chile. Ecotoxicol Environ Saf 80:386-392

Osawa T, Hatsukawa Y, Appel PWU, Matsue H (2011) Mercury and gold concentrations of highly polluted environmental samples determined using prompt gamma-ray analysis and instrument neutron activation analysis. Nucl Instrum Methods B 268:717-720

Palomo Marín MR, Pinilla Gil E, Calvo Blázquez L, Capelo-Martínez JL (2011) Determination of trace and major elemental profiles in street dust samples by fast miniaturized ultrasonic probe extraction and ICP-MS. Talanta 84:840-845

Pereira E, Rodrigues SM, Otero M, Válega M, Lopes CB, Pato P, Coelho JP, Lillebo IL, Pardal MA, Rocha R, Duarte AC (2008) Evaluation of an interlaboratory proficiency-testing exercise for total mercury in environmental samples of soils, sediments and fish tissue. TrAC 27:959-970

Reis AT, Rodrigues SM, Araújo C, Coehlo JP, Pereira E, Duarte AC (2009) Mercury contamination in the vicinity of a chlor-alkali plant and potential risks to local population. Sci Total Environ 407:2689-2700

Reis AT, Rodrigues SM, Davidson CM, Pereira E, Duarte AC (2010) Extractability and mobility of mercury from agricultural soils surrounding industrial and mining contaminated areas. Chemosphere 81:1369-1377 
Salminen R, Batista MJ, Bidovec M et al (2005) Geochemical atlas of Europe. Part 1: Background information, methodology and maps. Geological Survey of Finland, Espoo

Senesil GS, Baldassarre G, Senesi N, Radina R (1999) Trace element inputs into soils by anthropogenic activities and implications for human health. Chemosphere 39:343-377

Shoaee H, Roshdi M, Khanlarzadeh N, Beiraghi A (2012) Simultaneous preconcentration of copper and mercury in water samples by cloud point extraction and their determination by inductively coupled plasma atomic emission spectrometry. Spectrochim Acta A 98:70-75

Southworth GR, Lindberg SE, Zhang H, Anscombre FR (2004) Fugitive mercury emissions from a chlor-alkali factory: sources and fluxes to the atmosphere. Atmos Environ 38:597-611

Tack FMG, Vanhaesebroeck T, Verloo MG, Rompaey KV, Ranst EV (2005) Mercury baseline levels in Flemish soils (Belgium). Environ Pollut 134:173-179

Tadeo JL, Sánchez-Brunete C, Albero B, García-Valcárcel AI (2010) Application of ultrasound-assisted extraction to the determination of contaminants in food and soil samples. J Chromatogr A $1217: 2415-2440$
Terán-Mita TA, Faz A, Salvador F, Arocena JM, Acosta JA (2013) High altitude artisanal small-scale gold mines are hot spots for mercury in soils and plants. Environ Pollut 173:103-109

US EPA (2012) Regional screening level (RSL) for chemical contaminants, summary table

US EPA (1993) Reference dose (RfD): description and use in health risk assessments, background document 1A, integrated risk information system (IRIS). United States Environmental Protection Agency, Washington, DC

Wedepohl KH (1995) The composition of the continental crust. Geochim Cosmochim Acta 59:1217-1232

Wu Y, Wang S, Streets D, Hao J, Chan M, Jiang J (2006) Trends in anthropogenic mercury emissions in China from 1995 to 2003. Environ Sci Technol 40:5312-5318

Yang P, Mao R, Shao H, Gao Y (2009) An investigation on the distribution of eight hazardous heavy metals in the suburban farmland of China. J Hazard Mater 167:1246-1251

Yaylali-Abanuz G (2011) Heavy metal contamination of surface soil around Gebze industrial area, Turkey. Microchem J 99:82-92 